\title{
Rahner e a Liberdade do Teólogo
}

\author{
Luís Corrêa Lima
}

\section{Resumo}

No início da década de 1980, o papa João Paulo II interveio na Companhia de Jesus. O seu superior geral, padre Pedro Arrupe, ficara impossibilitado de governá-la por motivo de saúde. Um representante dele governava a instituição e a preparava para a eleição de um novo superior geral. O papa o substituiu, nomeando um delegado até a eleição do novo dirigente. O delegado pontifício emitiu normas restritivas sobre trabalho pastoral e a reflexão teológica dos jesuítas. Karl Rahner publicou um artigo analisando estas normas, no qual defende a liberdade de pesquisa e de expressão do teólogo como fundamentais para a própria teologia. A reconstituição daquele contexto, o argumento de Rahner e alguns desdobramentos são o tema desta comunicação.

Palavras-chave: Crise pós-conciliar, Magistério, Jesuítas, Divergência.

\begin{abstract}
In the early 1980s, Pope John Paul II intervened in the Society of Jesus. Their superior general, Father Pedro Arrupe, had been unable to rule it for health reasons. A representative of the institution ruled it and was preparing the election of a new superior general. The pope replaced him by appointing a delegate until the election of a new leader. The papal delegate issued restrictive standards on theological reflection and pastoral work of the Jesuits. Karl Rahner published a paper analyzing these standards, which defends
\end{abstract}


freedom of inquiry and expression as fundamental to the theologian's own theology. The reconstruction of that context, the Rahner's argument and some developments are the subject of this communication.

Keywords: Post-conciliar crisis, Magisterium, Jesuits, Disagreement.

Os anos que se seguiram ao Concílio Vaticano II foram de mudanças e inovações na vida da Igreja Católica, mas também de incertezas e resistências. O aggiornamento (atualização) desejado e convocado por João XXIII gerou crises e turbulências em diversos âmbitos eclesiais. Os institutos religiosos foram exortados pelo Concílio a se renovarem, em um regresso contínuo às fontes da vida cristã e à genuína inspiração de seus fundadores, e também na adaptação às novas condições dos tempos. Todos os institutos são chamados a participar da vida da Igreja, segundo sua própria índole, e a favorecer o quanto puderem as iniciativas eclesiais em matéria bíblica, dogmática, pastoral, ecumênica, missionária e social ${ }^{1}$.

$\mathrm{Na}$ Companhia de Jesus, esta renovação foi liderada pela figura carismática do padre Pedro Arrupe. Ele era basco e missionário no Japão, onde viveu o drama da Segunda Guerra Mundial e da explosão da bomba de Hiroshima. Em 1965, Arrupe foi nomeado superior geral do Instituto com o intuito de implementar a renovação conciliar. Os rumos desta renovação despertaram temores e oposições em muitos lugares, inclusive no papado e na Cúria Romana. João Paulo I morreu poucos dias antes de pronunciar um discurso severo aos membros da Companhia. Em 1981, quando se pensava na sucessão de Arrupe, João Paulo II manifestou-lhe a sua preocupação de que uma congregação geral da Companhia elegesse um superior da mesma linha² .

\section{A intervenção na Companhia de Jesus}

Nesse mesmo ano, uma trombose cerebral afastou Arrupe do generalato. Um representante dele assumiu o comando do Instituto, com a incumbência de convocar em breve uma congregação geral a fim de eleger um novo superior

\footnotetext{
${ }^{1}$ Decreto perfectae caritatis sobre a conveniente renovação da vida religiosa. Vaticano, 1965, n². Disponível em: <http://www.vatican.va/archive/hist_councils/ii_vatican_council/documents/ vat-ii_decree_19651028_perfectae-caritatis_po.html>. Acesso em: 21 ago. 2011.

${ }^{2}$ LAMET, Pedro Miguel. "20 años después de su muerte Arrupe vive”. Vida nueva (Colômbia), 4-17 jun. 2011, p. 27. Disponível em: http://www.vidanueva.co/files/2011/05/PORTADA-PLIEGO.pdf. Acesso em: 5 ago. 2011.
} 
geral. Foi então que o papa interveio na Companhia nomeando um delegado, o jesuíta Paolo Dezza, para dirigi-la até a realização desta nova congregação. A intervenção do papa causou profundo pesar ao padre Arrupe $^{3}$ e a muitos jesuítas, mas foi respeitada pelo Instituto e não houve rebelião.

Depois de se reunir com os superiores provinciais jesuítas, o delegado pontifício enviou uma carta a toda a Companhia ${ }^{4}$. Nela exortou sobre o desejo do papa de que os jesuítas contribuam eficazmente para a implementação do Concílio Vaticano II, assim como nos tempos de Santo Inácio não economizaram esforços para divulgar e aplicar o Concílio de Trento. O exercício do apostolado na Companhia deve levar em conta que as missões vêm do papa diretamente, ou do geral em virtude da concessão feita pelo sumo pontífice para representá-lo. É dever dos jesuítas seguir suas diretrizes, assim como todo enviado deve seguir as diretrizes de quem envia, aplicando-as corretamente em diferentes situações.

Convém observar, prossegue o delegado, que junto ao apostolado estritamente sacerdotal, como a pregação e os sacramentos, sempre se considerou conforme o Instituto outras atividades relacionadas com o sacerdócio, como o ensino das letras e das ciências, e outras ocupações, contanto que permaneça sempre a solicitude pelo caráter sacerdotal das atividades dos jesuítas, exercida sempre de maneira adequada a um instituto religioso ou sacerdotal. Às vezes estas atividades são feitas de maneira que a dimensão sacerdotal fica desconsiderada. Em alguns casos, quase desaparece uma verdadeira motivação apostólica ${ }^{5}$. Junto à formação intelectual é necessária uma sólida formação espiritual, religiosa e sacerdotal para não cair em uma progressiva secularização, que atinge a muitos empenhados no apostolado social e em outros apostolados. Isto leva inclusive a uma perda gradual da verdadeira motivação apostólica de sua atividade, que chega até o abandono da vocação religiosa e sacerdotal ${ }^{6}$.

Não se deve confundir, adverte ele, as tarefas próprias dos sacerdotes com as que são próprias dos leigos. Não é permitido aos jesuítas a participação em partidos políticos ou assumir postos diretamente políticos, a não ser em casos excepcionais aprovados pelos bispos e pelo padre geral. Além do mais, também esta atividade para a promoção da justiça deve ser desempenhada em harmonia com as orientações da hierarquia local ${ }^{7}$.

\footnotetext{
${ }^{3}$ Ibidem, p. 27.

${ }^{4}$ DEZZA, Paolo. "A toda la Compañia"(25 mar. 1982) e "Anejo: normas directivas...". Acta romana societatis iesu, $\mathrm{n}^{\circ} 3,1982$, p. 777-788.

${ }^{5}$ Ibidem, p. 780.

${ }^{6}$ Ibidem, p. 782.

${ }^{7}$ Ibidem, p. 781.
} 
Aí certamente se trata do descontentamento do papa e da Cúria Romana com a participação de Fernando Cardenal na Revolução Sandinista e no governo nicaragüense. Cardenal acabou expulso da Companhia. Muitos anos depois foi reintegrado. Havia também o caso do norte-americano Robert Drinan, deputado por massachusetts, politicamente a favor do aborto ${ }^{8}$.

Sobre a fidelidade ao magistério da Igreja, João Paulo II retomou a alocução que seu antecessor faria aos jesuítas ${ }^{9}$, assumindo-a como sua e comunicando-a ao padre geral. Nesta alocução, destaca o delegado, afirma-se que tem sido característica da Companhia o cuidado em apresentar na pregação, na direção espiritual, no ensino, na publicação de livros e revistas, uma doutrina sólida e segura plenamente conforme o ensinamento da Igreja. Deste modo a sigla 'S.J.' era uma garantia ao povo cristão, e um título meritório de confiança por parte do episcopado ${ }^{10}$.

As constituições do Instituto recomendam a doutrina mais segura e mais aprovada, exata e sólida, exorta Dezza. O respeito ao magistério autêntico ainda que não infalível deve ser observado, conforme ensina o Concílio Vaticano II, além do respeito religioso devido ao ensinamento dos bispos. Quando se trata de uma doutrina clara e repetidamente ensinada em documentos solenes, como as encíclicas, é um dever do ministro da Igreja comunicar aos fiéis, no ensino e na pregação, a doutrina autenticamente ensinada e ajudá-los a vivê-la. Isto necessita a fé na assistência do Espírito Santo prometido à Igreja e à sua cabeça visível, o romano pontífice, no seu ministério universal de conduzir os homens à salvação eterna ${ }^{11}$.

A liberdade de pesquisa científica, pondera o delegado, permanece intacta e deve reger-se somente pelas leis próprias do método teológico. Da parte dos jesuítas se deve evitar, fora dos círculos científicos, afirmações contrárias ao magistério para não confundir a mente dos fiéis. Estes esperam saber dos ministros da Igreja qual é a sua doutrina autêntica. É importante fomentar entre os jesuítas aquela atitude para com o magistério animada pelo espírito de fé, uma disposição favorável que leva a considerar íntegra e objetivamente os documentos magisteriais, apresentando-os de modo positivo e construtivo. $\mathrm{E}$ se ocorre alguma dificuldade que julgue manifestar, que o faça não de maneira

\footnotetext{
${ }^{8}$ LAMET, obra citada, p. 30.

${ }^{9}$ Em 21 de setembro de 1979.

${ }^{10}$ DEZZA, obra citada, p. 782.

${ }^{11}$ Ibidem, p. 783.
} 
agressiva e desconsiderada, mas com religioso respeito a quem está "revestido da autoridade de Cristo" 12 .

A Igreja peregrina nesta Terra é sempre necessitada de purificação, como diz o Concílio. A maneira mais adequada de melhorá-la não é a crítica pública e a contestação, mas o amor filial que sugere os meios mais aptos para corrigir e remediar, sem o barulho que provoca escândalo. Paulo VI, lembra Dezza, exorta os sacerdotes a amar a Igreja inclusive nos seus limites e defeitos. Não em razão destes limites e defeitos, ou até de suas culpas, mas porque somente amando-a podemos curá-la e fazer resplandecer a sua beleza de esposa de Cristo ${ }^{13}$.

Pode-se dizer que nesta carta do delegado pontifício estão contidas as principais preocupações e queixas do papa e da Cúria Romana, naquela época, a respeito da Companhia de Jesus. Muitas destas inquietações certamente vinham dos bispos e de outros segmentos das igrejas locais. Nos anos que se seguiram ao Concílio, houve uma crise na Igreja Católica. Por um lado, propunha-se uma visão positiva da sociedade contemporânea, incluindo a sã laicidade e a autonomia das ciências. O diálogo ecumênico e inter-religioso ganharam força. O Índice de Livros Proibidos foi extinto. A exaltação imoderada do sacerdócio e da vida religiosa deu lugar a uma valorização do laicato e do sacerdócio universal dos fieis. Por outro lado, a reforma litúrgica, com o abandono do latim e uma excessiva experimentação, o pluralismo ideológico e a contestação, um certo secularismo, um abandono massivo do sacerdócio e da vida religiosa, trouxeram insegurança a muitos fieis e reações da hierarquia. A carta de Dezza é parte desta crise pós-conciliar.

\section{A resposta de Rahner}

Depois da publicação da carta do delegado pontifício, Karl Rahner escreveu um artigo comentando-a ${ }^{14}$. Logo no início, ele diz que não quer falar de maneira desrespeitosa. Entretanto, em caso de conflito entre honestidade e respeito, ele é a favor da honestidade. A ausência de dificuldades entre a Companhia de Jesus e o Vaticano não seria um sinal de saúde. Somente os mortos e os grupos fossilizados em seu conservadorismo não têm dificul-

\footnotetext{
${ }^{12}$ Ibidem, p. 783-784.

${ }^{13}$ Ibidem, p. 785.

${ }^{14}$ RAHNER, Karl. “Zur Situation des Jesuitenordens nach den Schwierigkeiten mit dem Vatikan”. Schriften zur Theologie - XV. Zurique, Einsiedeln, Colônia: Benziger, 1983, p. 355-373. Tradução em ingês: "The situation of the Society of Jesus since its difficulties with the Vatican". Theological investigations - 23. Nova Iorque: Crossroad, 1992, p. 89-106.
} 
dades. As normas de vida prática do século XVIII, por exemplo, não devem reger os que vivem no presente ${ }^{15}$.

Parece a Rahner que as declarações romanas frequentemente estão embasadas em uma noção de Igreja não facilmente perceptível, e certamente não explicitada, que ele considera falsa do ponto de vista dogmático, humano e realista. Tem-se a impressão de que se pressupõe que toda a atividade verdadeira e legítima na Igreja, todas as iniciativas e idéias, procedem da mais alta autoridade romana, ou ao menos não podem ser legitimadas até que tenham a aprovação explicita ou tácita de Roma. Um noção de Igreja que na esfera secular seria chamada totalitária, e que está errada ${ }^{16}$.

Tudo o que ocorre em nome de Jesus, prossegue ele, deve em última instância ocorrer fundamentalmente dentro da Igreja e da sua unidade, e tudo o que de fato ocorre fora da Igreja sob a inspiração do Evangelho contém um dinamismo interno orientado para a única Igreja de Jesus Cristo. Mesmo que isto seja verdade, e mesmo que a Santa Sé tenha a responsabilidade última pela unidade desta Igreja na medida em que ela estiver presente na sociedade, uma responsabilidade acima de qualquer poder terrestre, isto não significa que não possa haver um pluralismo de iniciativas e caminhos de se formar a vida cristã ${ }^{17}$.

Historicamente há sempre um tipo de pluralismo que desde o início não é inaugurado ou formado por Roma, pondera Rahner, mesmo que alguém formalmente queira ver no pluralismo sem contradição com Roma uma aprovação tacitamente concedida. Este pluralismo é legítimo. Os primeiros padres do deserto partiram para o deserto sem uma aprovação explícita que lhes seria necessária. O pobre de Assis devolveu suas roupas a seu pai sem ter a aprovação da Igreja oficial. O culto do Sagrado Coração de Jesus surgiu e se propagou quando em Roma não se queria ouvir falar disso. A nova exegese surgiu em meio à oposição da Comissão Bíblica sob Pio X. Santa Teresa d'Ávila fundou seus conventos tendo grandes dificuldades com Roma. Na disputa entre as associações de trabalhadores católicos e as uniões cristãs trabalhistas no tempo de Pio $\mathrm{X}$, os jesuítas alemães certamente não correspondiam aos desejos e intenções do papa, mas mesmo assim estavam certos. Santo Inácio de Loyola não teria tremido com a eleição do Papa Paulo IV se não tivesse havido tendências na Igreja, desde o início, para que a Santa Sé não desse sua

\footnotetext{
${ }^{15}$ Idem, "The situation of the Society..., o.c., p. 91.

${ }^{16}$ Ibidem, p. 93.

${ }^{17}$ Ibidem, p. 94.
} 
benção à Companhia ${ }^{18}$. O maior obstáculo à beatificação de Vicente Palotti, hoje canonizado, é o fato de ele ter tido certa vez que Pio IX era tapado ${ }^{19}$.

Rahner inclui a si mesmo, lembrando que a censura prévia a ele imposta antes do Concílio nunca foi revogada, nem pelo Santo Ofício (como então era chamada a Congregação para a Doutrina da Fé), nem pela cúria geral dos jesuítas. Sendo assim, esta censura ainda estaria em vigor. Na relação com Roma, conclui, não se deve agir como se um pluralismo legítimo não existisse na Igreja, como se todos fossem executores das ordens e desejos da Santa Sé. O Espírito Santo não tem iniciativas na Igreja apenas e exclusivamente através do papa $^{20}$.

O ensinamento papal, mesmo que não contenha definições dogmáticas, deve em princípio ser devidamente respeitado. É óbvio, concorda Rahner, que a crítica a um pronunciamento papal deve ser feita manifestando um respeito básico pelo ofício eclesiástico de ensinar. Este tipo de crítica não deve ser feito em sermões ou na catequese. Citando uma instrução dos bispos alemães de 1967, ele acrescenta: um esforço sério para avaliar positivamente, e assimilar mesmo uma declaração doutrinal provisória da Igreja, é parte da atitude de fé de um católico. E deve ser especialmente de um jesuíta ${ }^{21}$.

Os bispos alemães reconhecem, lembra Rahner, que não se pode negar que há casos onde a consciência bem informada dos cristãos, e dos jesuítas, pode discordar de um ensinamento autoritativo, sem lhe dar assentimento, e expressar-se com o devido respeito porque o ofício eclesiástico de ensinar pode errar, e tem errado em meras declarações doutrinárias autoritativas. Isto não está devidamente tratado na carta do padre Dezza, onde há conclusões inaceitáveis mesmo para o mais eclesial dos teólogos jesuítas. A insistência nestas conclusões causaria grande dano a uma teologia objetiva e responsável. A teologia dos jesuítas ficaria desacreditada aos olhos do público, gerando-se um clima de desonestidade. Ela seria vista como um mero porta-voz de um poder docente autoritário ${ }^{22}$.

De acordo com Dezza, uma posição crítica de um jesuíta sobre um ensinamento oficial pode ser apresentada apenas privadamente ao magistério romano. Não se permite nem a publicação de posições críticas em jornais

\footnotetext{
${ }^{18} \mathrm{Idem}$.

19 “...daß er einmal gesagt hat, Pius IX. habe ein Brett vor dem Kopf” (RAHNER, “Zur Situation des Jesuitenordens..., o.c., p. 361).

${ }^{20}$ RAHNER. "The situation of the Society.... O.c., p 94-95.

${ }^{21}$ Idem.

${ }^{22}$ Ibidem, p. 96
} 
científicos. Mas proibi-las ou impedi-las, afirma Rahner, significaria a morte da teologia. Como se poderia esperar seriamente fazer progressos absolutamente necessários para a eficácia do evangelho e para a fé da Igreja, se todo avanço devesse primeiramente ter a bênção do magistério romano que, pelo menos até agora, em muitos casos tomou posições objetivamente erradas? No tempo de Pio X, como alguém poderia ter posições hoje aceitas pelo conjunto dos exegetas católicos, do Antigo e do Novo Testamento, se a aprovação prévia para isto fosse requerida à Comissão Bíblica? Como o ensinamento dos vínculos biológicos entre o ser humano e o mundo animal teria sido possível - um ensinamento que até foi permitido por Pio XII em 1950 - se todos os teólogos e biólogos entre o tempo de Darwin e meados do século XX tivessem que ter a aprovação prévia de Roma ${ }^{23}$ ?

$\mathrm{O}$ fato é que o magistério eclesiástico pode errar e tem errado muitas vezes, mesmo no século $\mathrm{XX}$, e que concretamente estes erros prejudiciais à mensagem cristã só podem ser superados se a crítica pública for possível, defende Rahner, por mais cautelosa e respeitosa que seja. Dezza nem menciona a possibilidade do magistério errar e ter errado, algo que os bispos alemães explicitamente admitiram. Se a possibilidade de divulgar uma objeção nos meios de comunicação social for excluída, então parece que as posições críticas também no nível científico estão excluídas por Dezza. Mas isto seria a morte da teologia no serviço à salvação das almas. Se o magistério pode errar em seu ensinamento, como seguir esta exigência do delegado pontifício de que o ensinamento jesuítico "deve estar em total concordância com o do magistério", sempre e absolutamente? Se isto for levado a sério total e completamente, os jesuítas seriam obrigados a ensinar, defender e propagar erros mesmo quando os reconhecessem como tais, e sustentá-los até que o magistério os revogasse explicitamente ${ }^{24}$.

O que deve fazer um teólogo jesuíta, pergunta-se Rahner, quando um leigo católico instruído o interroga sobre uma questão teológica em que a consciência do jesuíta honestamente só lhe permite repetir e defender o ensinamento autoritativo, mas não definitivo? Quando se trata de uma questão de sua própria consciência e a da salvação da alma de quem pergunta, pode o jesuíta comunicar sua própria convicção quando diverge do magistério romano? Seria ele autorizado a fazê-lo, por exemplo, já em 1930 a respeito da origem biológica do ser humano, mesmo que Roma não tenha permitido explicitamente até 1950 ?

\footnotetext{
${ }^{23}$ Ibidem, p. 97-98.

${ }^{24}$ Ibidem, p. 99.
} 
Como deve o jesuíta esconder sua opinião, talvez compartilhada pela maioria dos teólogos morais na Alemanha que não estão de pleno acordo com o ensinamento da Humanae vitae? Se a cúria geral do Instituto vai dar instruções úteis aos teólogos jesuítas, terá que contemplar questões como estas ${ }^{25}$.

As instruções do padre Dezza não possuem um entendimento plenamente realista do ofício do teólogo, conclui Rahner. Tomando-as simplesmente pelo que dizem, é inevitável concluir que o ofício do teólogo é aceitar, explicar e defender o ensinamento explícito do magistério ${ }^{26}$. Em vista disso, com o devido respeito ao delegado pontifício, Rahner expressa o seu desejo de que, antes da publicação de instruções deste tipo, sejam ouvidos teólogos realmente competentes que entendam todos os elementos e as dificuldades contidas nestas questões, e que possuam experiência em seu campo de trabalho ${ }^{27}$.

Ele ainda faz considerações sobre outras questões, como a promoção da justiça. Esta deve estar "de acordo com as diretrizes da hierarquia local". Mas deve-se admitir que em situações concretas da vida esta norma não deve ser o único princípio que governa a ação. Nesta área, podem surgir conflitos semelhantes aos do magistério na área teórica da teologia. Aí também, para promoção da justiça, a obediência não deve ser simplesmente obediência cega. Finalmente, as normas abstratas sozinhas são insuficientes para superar conflitos também neste campo ${ }^{28}$.

Nas posições de Dezza e de Rahner estão presentes, de certa maneira, duas concepções de sociedade que incidem na Igreja e na teologia. A primeira é a tradicional e orgânica, que estima a harmonia, a concórdia, e a subordinação regulada e controlada das partes ao todo. Condena-se o conflito aberto como elemento de desordem e de desagregação. As normas das constituições dos jesuítas citadas por Dezza, sobre adotar a doutrina mais segura e mais aprovada, vão nesta linha. Elas foram redigidas no século XVI, no ambiente da Contra-Reforma. Era tal a desconfiança a respeito das heresias, que o Concílio de Trento acabou formulando mais de cem anátemas. Rahner, por sua vez, vincula-se a uma concepção que valoriza o contraste entre indivíduos e grupos, na qual se explicita a contraposição de opiniões, e se realiza o debate aberto de ideias na busca da verdade. É uma concepção em que o antagonismo é fecundo ${ }^{29}$, compartilhada pelas sociedades liberais e democráticas.

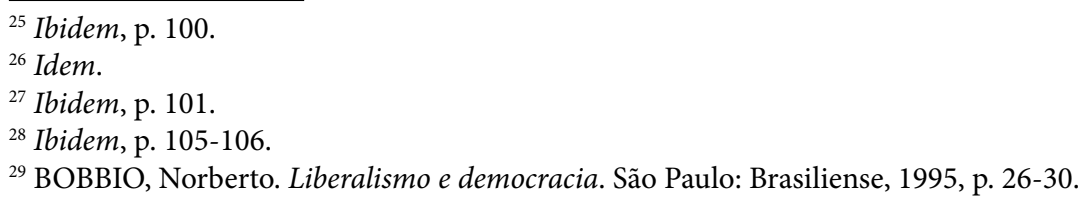




\section{A Instrução romana Donum veritatis}

A controvérsia a respeito da relação entre o teólogo e o magistério da Igreja, levou a Cúria Romana a publicar uma instrução emitindo normas sobre o tema ${ }^{30}$. Em razão do mandato divino que lhe foi dado na Igreja, afirma a Instrução, o magistério tem a missão de propor o ensinamento do evangelho, velar sobre a sua integridade, e assim proteger a fé do povo de Deus. No caso de um teólogo encontrar sérias dificuldades para acolher um ensinamento magisterial não irreformável, por razões que lhe parecessem fundadas, jamais deve arrefecer nele uma atitude de fundo de disponibilidade para este acolhimento leal, como convém a todo fiel, em nome da obediência da fé ${ }^{31}$.

O teólogo se esforçará para compreender este ensinamento no seu conteúdo, nas suas razões e nos seus motivos, exorta a Instrução. Para isto, ele deve consagrar uma reflexão aprofundada e paciente, pronto para rever suas próprias opiniões e examinar as objeções que lhe sejam feitas pelos seus colegas. Se apesar de um leal esforço as dificuldades persistirem, é dever do teólogo informar às autoridades magisteriais os problemas suscitados pelo ensinamento, pelas justificações propostas e pela maneira como é apresentado. Ele o fará com espírito evangélico e profundo desejo de resolver as dificuldades. As suas objeções poderão então contribuir para um real progresso, estimulando o magistério a propor o ensinamento da Igreja de maneira mais aprofundada e melhor argumentada ${ }^{32}$.

Neste caso, porém, o teólogo deve evitar recorrer aos 'mass-media' ao invés de se dirigir à autoridade responsável. Não é exercendo pressão sobre a opinião pública, prossegue a Instrução, que se pode contribuir para o esclarecimento dos problemas doutrinais e servir à verdade. Pode ainda ocorrer que, ao final de um exame sério do ensinamento do magistério e conduzido com uma vontade de escuta sem reticências, a dificuldade permaneça porque os argumentos opostos parecem ao teólogo prevalecer. Diante de uma afirmação à qual sinta não poder dar sua adesão intelectual, o seu dever é de permanecer disponível para um exame mais aprofundado da questão ${ }^{33}$.

${ }^{30}$ CONGREGAÇÃO PARA A DOUTRINA DA FÉ. Instrução Donum veritatis sobre a vocação eclesial do teólogo. Roma, 1990. Disponível em: <http://www.vatican.va/roman_curia/congregations/cfaith/documents/rc_con_cfaith_doc_19900524_theologian-vocation_po.html>. Acesso em: 19 ago. 2011.

${ }^{31}$ Ibidem, no37, 28 e 29.

${ }^{32}$ Ibidem, n²8-30.

${ }^{33}$ Ibidem, n³0-31. 
Para um espírito leal e animado pelo amor à Igreja, uma tal situação pode certamente representar uma prova difícil, reconhece a Instrução. Pode ser um convite a sofrer no silêncio e na oração, com a certeza de que se a verdade está de fato em questão, ela terminará necessariamente por se impor. Por outro lado, o teólogo que não está em sintonia com o 'sentire cum Ecclesia'34, coloca-se em contradição com o compromisso livre e conscientemente assumido por ele de ensinar em nome da Igreja. A argumentação que se refere ao dever de seguir a própria consciência, não pode legitimar a dissensão ${ }^{35}$.

Para velar sobre a integridade do ensinamento do evangelho e proteger a fé do povo de Deus, às vezes o magistério pode ser levado a tomar graves providências, justifica a Instrução, como retirar de um teólogo que se afasta da doutrina da fé, a missão canônica, ou o mandato de ensinamento que lhe havia confiado, ou mesmo declarar que alguns escritos não estão de acordo com esta doutrina. Agindo dessa forma, o magistério entende ser fiel à sua missão, porque defende o direito do povo de Deus de receber a mensagem da Igreja na sua pureza e na sua integridade, e assim a não ser perturbado por uma perigosa opinião particular ${ }^{36}$.

\section{Outros desdobramentos e considerações}

A questão da liberdade do teólogo e a relação com o magistério continuou na pauta dos jesuítas. Uma congregação geral do Instituto, realizada em 1995, retomou a questão. No início dela, João Paulo II discursou aos delegados, retomando uma importante consideração de Paulo VI sobre a missão da Companhia: "onde quer que na Igreja, mesmo nos campos mais difíceis e da primeira linha, nas encruzilhadas ideológicas, nas trincheiras sociais, existiu ou existe conflito entre as prementes exigências do homem e a mensagem perene do Evangelho, aí estiveram e estão os jesuítas"37.

Sobre o sentido verdadeiro que se deve ter no serviço da Igreja, diz a Congregação, o estudioso ou o teólogo jesuíta deve procurar manter a respeitabilidade da tradição cristã, como uma visão coerente e válida de mundo, em diálogo com os âmbitos da pesquisa e da ciência seculares. Registram-se fortes tensões interiores na Igreja, que necessariamente têm de atingir os jesuítas.

\footnotetext{
${ }^{34}$ Sentir com a Igreja, a fim de agir em consonância com ela.

${ }^{35}$ Ibidem, n' 31 e 38 .

${ }^{36}$ Ibidem, n⿳3十.

37 "Discurso de sua santidade o papa João Paulo II" (5 jan. 1995), nº 8. Decretos da congregação geral XXXIV. São Paulo: Loyola, 1996, p. 316.
} 
Pela responsabilidade apostólica que possuem, não podem deixar de se envolver em situações eclesiais conflitivas, e até mesmo explosivas. Sua resposta a tais situações pode causar tensões com algumas autoridades eclesiásticas. Apesar do desejo sincero de serem fiéis ao magistério e à hierarquia, e precisamente por isso, pode haver momentos em que os jesuítas se sintam obrigados a falar de uma maneira que nem sempre obtenha a aprovação geral, e até conduza a sanções dolorosas para a Companhia ${ }^{38}$.

Agir assim não significa desobediência ou rebeldia, defende a Congregação. A obediência de Inácio de Loyola, em consonância com a tradição da teologia católica, reconheceu sempre que a fidelidade primeira deve ser a Deus, à verdade e a uma consciência bem formada. A obediência não exclui o discernimento em oração sobre o plano de ação a ser seguido. Em certas circunstâncias, este plano pode ser diferente daquele sugerido pelos superiores religiosos e eclesiásticos. Tal discernimento e sua manifestação respeitosa aos superiores é um elemento genuíno da tradição inaciana ${ }^{39}$.

Pode-se notar que a Congregação Geral não fomenta o dissenso, mas contempla as razões e as motivações daqueles que divergiram. $\mathrm{O}$ então superior geral da Companhia de Jesus, Peter-Hans Kolvenbach, anos depois comentou o pronunciamento de Paulo VI sobre a presença constante dos jesuítas nas 'trincheiras' e nas 'encruzilhadas'. Nelas se têm debatido problemas que nem sempre têm uma resposta nítida ${ }^{40}$.

Não é estranho, observa Kolvenbach, que no serviço da Igreja alguns tenham abandonado a segurança das trincheiras, para lançar-se a peito descoberto mais além das 'demarcações ortodoxas', em busca de novas respostas a novos problemas. Um exemplo esclarecedor é o caso de Mateo Ricci, que foi um missionário italiano na China no final do século XVI e início do século XVII. Ricci foi um conhecedor profundo da cultura e da mentalidade chinesas. Ele se esforçou para mostrar que a reverência aos antepassados não era um culto idolátrico, como se dizia no Ocidente, mas um costume social e familiar que não contradizia a fé cristã, nem justificava que se negasse o batismo aos que desse modo recordavam seus antepassados. Esta postura fez cair sobre ele críticas de outros religiosos e, finalmente, a condenação de Roma ${ }^{41}$.

\footnotetext{
${ }^{38}$ Decretos da congregação geral XXXIV, o.c., Decr. 11, nº12 e 13.

${ }^{39}$ Ibidem, $\mathrm{n}^{\circ} 14$.

${ }^{40} \mathrm{KOLVENBACH}$, Peter-Hans. "Superior dos jesuítas explica por que convocou a Congregação Geral”. Zenit, 28 ago. 2006. Disponível em: <http://www.zenit.org/article-12104?l=portuguese>. Acesso em: 20 ago. 2011.

${ }^{41}$ Idem.
} 
Sem dúvida que isso fechou a porta a muitas possíveis conversões, prossegue Kolvenbach. Somente no século XX Ricci foi reconhecido como um vanguardista na proclamação do evangelho, e como precursor da inculturação no trabalho missionário. Nem todos os jesuítas que foram chamados a Roma para dar esclarecimentos, podem atribuir-se a preparação e a nobreza de intenções de Ricci, mas não são poucos os que têm servido à Igreja com uma fidelidade e uma dedicação que não se reconhecem até se passar muito tempo. Teilhard de Chardin provavelmente é um dos casos mais representativos ${ }^{42}$.

O tema do desacordo com o magistério também foi tratado por YvesMarie Congar, teólogo dominicano, especialista em eclesiologia. Ele foi afastado da docência por Pio XII, e anos depois foi chamado para participar do Concílio Vaticano II como perito. Um dos exemplos citados por Congar é o de Robert Grossetête, bispo inglês e erudito da Idade Média, que escreveu uma carta na qual se recusa de modo absoluto a ceder ao papa. Ele apresenta a fórmula "obedienter recuso et rebello", ou seja, é ao recusar, e ao recusar submeter-me, que me mostro obediente. Outro exemplo é o do partido católico alemão Zentrum, ao qual Leão XIII pediu que aprovasse leis militares a fim de fazer a paz com o governante Bismarck. O Zentrum se recusou ${ }^{43}$.

Há ainda os exemplos de Lutero, do biblista Alfred Loisy, excomungado no início do século XX, e dos padres operários, proibidos por Pio XII. A conclusão de Congar sobre esta questão é a seguinte: tem-se direito à divergência quando se tem o dever de fazê-lo, em nome de uma verdade reconhecida, seja ela a verdade bíblica histórica (Loisy), a verdade apostólica (padres operários), a verdade pastoral (Grossetête) ou a verdade política (o Zentrum). Tem-se o direito quando se tem o dever ${ }^{44}$.

A questão tratada por Rahner sobre a liberdade do teólogo e a relação com o magistério, é parte de uma questão mais ampla sobre a fidelidade a Deus e à Igreja. $\mathrm{O}$ evangelho, as circunstâncias concretas da realidade e as exigências da missão, podem gerar conflitos com a autoridade e as estruturas da Igreja. A história registra muitas divergências onde não faltam, nas partes antagônicas, zelo apostólico e amor verdadeiro. Ao que tudo indica, parece que não há soluções plenamente satisfatórias e universalmente válidas. Mas esta história é sempre fascinante e ilumina os conflitos, que estão longe de terminar.

\footnotetext{
${ }^{42}$ Idem.

${ }^{43}$ CONGAR, Yves-Marie. Diálogos de outono. São Paulo: Loyola, 1990, p. 69.

${ }^{44}$ Idem.
} 


\section{Referências Bibliográficas}

BOBBIO, Norberto. Liberalismo e democracia. São Paulo: Brasiliense, 1995.

CONGAR, Yves-Marie. Diálogos de outono. São Paulo: Loyola, 1990.

CONGREGAÇÃO PARA A DOUTRINA DA FÉ. Instrução Donum veritatis sobre a vocação eclesial do teólogo. Roma, 1990. Disponível em: <http:// www.vatican.va/roman_curia/congregations/cfaith/documents/rc_con_cfaith_ doc_19900524_theologian-vocation_po.html . Acesso em: 19 ago. 2011.

Decreto perfectae caritatis sobre a conveniente renovação da vida religiosa. Vaticano, 1965, n². Disponível em: <http://www.vatican.va/archive/ hist_councils/ii_vatican_council/documents/vat-ii_decree_19651028_ perfectae-caritatis_po.html>. Acesso em: 21 ago. 2011.

Decretos da congregação geral XXXIV. São Paulo: Loyola, 1996.

DEZZA, Paolo. "A toda la Compañia"(25 mar. 1982) e "Anejo: normas directivas...". Acta r omana societatis iesu, n³, 1982, p. 777-788.

KOLVENBACH, Peter-Hans. "Superior dos jesuítas explica por que convocou a Congregação Geral". Zenit, 28 ago. 2006. Disponível em: http://www. zenit.org/article-12104?1=portuguese Acesso em: 20 ago. 2011.

LAMET, Pedro Miguel. "20 años después de su muerte Arrupe vive". Vida nueva (Colômbia), 4-17 jun. 2011, p. 23-30. Disponível em: <http://www.vidanueva. co/files/2011/05/PORTADA-PLIEGO.pdf >. Acesso em: 5 ago. 2011.

RAHNER, Karl. "Zur Situation des Jesuitenordens nach den Schwierigkeiten mit dem Vatikan". Schriften zur Theologie - XV. Zurique, Einsiedeln, Colônia: Benziger, 1983, p. 355-373. Tradução em ingês: "The situation of the Society of Jesus since its difficulties with the Vatican". Theological investigations - 23. Nova Iorque: Crossroad, 1992, p. 89-106.

\section{Luís Corrêa Lima}

Padre Jesuíta, Doutor em História pela Universidade de Brasília Professor do Departamento de Teologia da PUC-Rio Membro do seu programa de Pós-Graduação

E-mail: 1clima@puc-rio.br

Artigo Recebido em 22/08/2011 Artigo Aprovado em 25/11/2011 